\title{
Frequency of postpartum depression among primi mothers undergoing delivery in JIPMER using Edinburgh postnatal depression scale
}

\author{
Gowsalya Selvam, Janarthanan Balasubramanian, Sairem Mangolnganbi Chanu \\ Correspondence: Mr. Janarthanan Balasubramanian. Tutor, College of Nursing, JIPMER, \\ Puducherry, India. Email - gowsalyatv1198@gmail.com
}

Distributed under Attribution-NonCommercial - Share Alike 4.0 International (CC BY-NC-SA 4.0)

\begin{abstract}
Objective: To assess the prevalence of postpartum depression among primi mothers in JIPMER and to compare the level of postpartum depression among LSCS (Lower Segment Cesarian Section) and vaginal delivery mothers. Methods: A cross-sectional study was conducted among 200 postnatal primi mothers who underwent delivery in JIPMER. Among them 100 vaginal delivery mothers and 100 LSCS mothers were selected by using systematic random sampling method. Data collection was done by using Edinburgh Postnatal Depression Scale (EPDS). All statistical analyses were done by using frequency, percentage and unpaired t-test. Results: The study revealed that the prevalence of postnatal depression among the primi mothers was $12 \%$, level of depression was high among vaginal delivery mothers (12\%) than the mothers underwent LSCS. The unpaired $t-$ test shows a p-value $(0.001)$ which was highly significant. It was also evident that pain after delivery, and breastfeeding problem were related with postnatal depression. Conclusion: Prevalence of postpartum depression is high among primi mothers which enabled us to make the antenatal counselling more effective regarding the delivery and its complications, among the mothers.
\end{abstract}

Keywords: Postpartum, depression, primi.

Being pregnant is the happiest and memorable event in a life of a woman. She may experience various changes in her body not only the physical changes and also the mental, social, and psychological changes may exist. In these the physical but problems can be easily recognizable and can be managed at an early period, but the mental or emotional changes cannot be identified easily. The psychological complications arising due to pregnancy and postpartum period include postnatal depression, psychosis and blues. Among this, postnatal depression is common among women at this stage.

The global prevalence of postpartum depression is about $7.6 \%$ to $39 \%$. This is based on the population being studied and the screening tool used to identify the postpartum depression level among the women in various regions of the world. ${ }^{1-3}$ Developing countries may exhibit higher occurrence rate of postpartum depressive symptoms ranging from $10 \%$ to $42 \%$ than the developed ones among the various countries. ${ }^{4,5}$

Postpartum depression is the most commonly

Received: $2^{\text {nd }}$ September 2019. Accepted: $13^{\text {th }}$ November 2019.

Selvam G, Balasubramanian J, Mangolnganbi Chanu S. Frequency of postpartum depression among primi mothers undergoing delivery in JIPMER using Edinburgh postnatal depression scale. The New Indian Journal of OBGYN. 2020; 6(2): $106-12$. 
prevailing psychological problem of early motherhood due to unemployment of both the mother and the household, not breastfed the baby, not a planned pregnancy. ${ }^{6}$ Postpartum depression is not only affecting the mother and it also have an impact on the spouse in their relationships, and on the children. So, it is important to detect it at the earliest and managing it to prevent the further problems arising due to this. ${ }^{7}$ The meta-analysis of various studies showed that, the children of a postpartum depressive mother may have a chance of being stunted and overweight. ${ }^{8}$

Edinburgh Postnatal Depression Scale (EPDS) is the most commonly used screening tool for the identification of postnatal depression in pregnant women and also in the postnatal mothers due to its effectiveness and accuracy. ${ }^{9}$ This scale is effective and can be used in obstetrical settings for diagnostic and screening purposes in early postnatal period.

The occurrence of postpartum depression is left unnoticed due to not giving more importance to the psychological problems during pregnancy rather than the physical problems and also due to various reasons like the women may not coming for proper follow-up care to the hospital, social stigma etc.

If this postnatal depression is not treated, may lead to recurrent episode of depression which is a long term and chronic complication of the postpartum depression. The children of those mother who is experiencing depression will exhibit issues in physical, interpersonal, emotional, behavioral and cognitive wellbeing in their adulthood. ${ }^{10}$

Though the occurrence of depression in postnatal period is high and common, it is left undiagnosed and hence not treated and managed. ${ }^{11,12}$

Objectives: 1) To assess the prevalence of postpartum depression among primi mothers in JIPMER. 2) To compare the level of postpartum depression among LSCS (Lower Segment Cesarian Section) and vaginal delivery mothers.

\section{Materials and Methods}

A cross sectional study was conducted in postnatal and LSCS wards in JIPMER after getting approval from the Institutional Ethical Committee. The participants who met the inclusive criteria were selected as study participants. They were explained about the study, then the written consent was obtained from them. The socio-demographic data and the data about the depression were collected from them using the Edinburgh Postnatal Depression Scale (EPDS) which is a standardized scale to assess the postpartum depression in local language Tamil. ${ }^{13}$ The mothers were provided with privacy and interviewed in a comfortable manner. The data were collected for the period of three months.

\section{Inclusion criteria}

- Mothers aged above 18 years.

- Who underwent LSCS or vaginal delivery within 3 to 5 days of delivery.

- Who can able to read and understand Tamil.

\section{Exclusion criteria}

- Mothers who recently diagnosed with mental problems like anxiety disorder, panic attack etc.

- Mothers with critically ill conditions.

Sample size is calculated by using the prevalence of postnatal depression from previous study in which the prevalence of postpartum depression is $13.6 \%{ }^{14}$ and also according to the previous census of deliveries conducted in Women and Children Hospital in JIPMER, on an average of 15 vaginal delivery and 10 LSCS were conducted in a day. For a period of three months of data collection the expected delivery rate will be of 2250 (both spontaneous vaginal delivery and LSCS) and the sample size is calculated as 168. And it is rounded off into 200 . The sample size is estimated at $5 \%$ level of significance and $5 \%$ level of absolute precision.

Sampling technique: Systematic random sampling technique will be used.

$\mathrm{K}=2000$ (total number deliveries in a day) $/ 200$ (sample size)

$\mathrm{K}=10$. So, every $10^{\text {th }}$ case will be taken as a sample.

Data collection methods: Data collection were done as a structured interview method using Edinburgh Postnatal Depression Scale (EPDS).

Tool description: Section I- Includes 3 Parts A, B \& C which contains socio-demographic details, socio-cultural factors and delivery factors respectively. Section II Includes Edinburgh Postnatal Depression Scale (EPDS) the scale consists of 10 short statements. Responses are scored $0,1,2$ and 3 based on the seriousness of the symptom. Items 3, 5 to 10 are reverse scored (i.e. 3, 2, land 0 ). The total score is found by adding together the scores of each of the items. Mothers scoring above 12 or 
13 are likely to be suffering from depression and should seek medical attention.

List of variables and their measurement methods with standardization techniques

* Independent variables

Socio-demographic factors: age of mother, couple status, religion, age of husband, educational status of the mother, educational status of the husband, occupation of the mother, occupation of the husband, family income,
Socio-cultural factors: type of marriage, duration of marriage life, type of family, relationship with husband, relationship with in-laws, available family support, gender preference, history of substance use in husband, family history of psychiatric illness.

Delivery factors: type of delivery, pain after delivery, sex of baby, low birth weight, breastfeeding problem, planned pregnancy, previous abortion, maternal comorbidities like gestational diabetes mellitus,

Table 1: Frequency and percentage wise distribution of demographic variables among primi mothers undergoing delivery in JIPMER ( $\mathbf{N}=\mathbf{2 0 0})$

\begin{tabular}{|c|c|c|c|c|c|c|}
\hline \multirow{2}{*}{\multicolumn{2}{|c|}{$\begin{array}{l}\text { Demographic } \\
\text { Variables }\end{array}$}} & \multicolumn{2}{|c|}{ LSCS } & \multicolumn{2}{|c|}{ Vaginal delivery } & \multirow{2}{*}{$\begin{array}{c}\text { Statistical } \\
\text { significance }\end{array}$} \\
\hline & & \multirow[t]{2}{*}{$\mathbf{N}$} & \multirow{2}{*}{$\begin{array}{r}\% \\
52\end{array}$} & \multirow{2}{*}{\begin{tabular}{|l}
$\mathbf{N}$ \\
58
\end{tabular}} & $\%$ & \\
\hline Mothers age & $19-23$ & & & & 58 & $\mathrm{x}^{2}=1.977 ; \mathrm{df}=2, \mathrm{p}$-value $=0.372$ \\
\hline in years & $24-28$ & 41 & 41 & 39 & 39 & \\
\hline & $29-34$ & 7 & 7 & 3 & 3 & \\
\hline \multicolumn{2}{|c|}{ Mean age in years } & \multicolumn{2}{|c|}{$23 . \overline{7}$} & \multicolumn{2}{|c|}{23.1} & $\mathrm{t}=1.475 ; \mathrm{df}=198, \mathrm{p}$-value $=0.142$ \\
\hline \multirow{2}{*}{$\begin{array}{l}\begin{array}{l}\text { Couple } \\
\text { status }\end{array} \\
\end{array}$} & Staying together & 93 & 93 & 88 & 88 & \multirow[t]{2}{*}{$\mathrm{x}^{2}=1.454 ; \mathrm{df}=1, \mathrm{p}$-value $=0.228$} \\
\hline & Staying separated & 7 & 7 & 12 & 12 & \\
\hline \multirow{3}{*}{ Religion } & Hindu & 91 & 91 & 92 & 92 & \multirow{3}{*}{$\mathrm{x}^{2}=1.691 ; \mathrm{df}=2, \mathrm{p}$-value $=0.429$} \\
\hline & Muslim & 5 & 5 & 2 & 2 & \\
\hline & Christian & 4 & 4 & 6 & 6 & \\
\hline \multirow{3}{*}{$\begin{array}{l}\text { Husband } \\
\text { age in years }\end{array}$} & $20-30$ & 65 & 65 & 77 & 77 & \multirow[t]{3}{*}{$\mathrm{x}^{2}=4.137 ; \mathrm{df}=2, \mathrm{p}$-value $=0.126$} \\
\hline & $31-40$ & 34 & 34 & 23 & 23 & \\
\hline & $>40$ Years & 1 & 1 & 0 & 0 & \\
\hline \multicolumn{2}{|c|}{ Mean age in years } & \multicolumn{2}{|c|}{29.6} & \multicolumn{2}{|c|}{28.6} & $\mathrm{t}=2.173 ; \mathrm{df}=198, \mathrm{p}$-value $=0.031^{*}$ \\
\hline \multirow{6}{*}{$\begin{array}{l}\text { Literacy of } \\
\text { the mother }\end{array}$} & Illiterate & 1 & 1 & 0 & 0 & \multirow{6}{*}{$\mathrm{x}^{2}=6.319 ; \mathrm{df}=5, \mathrm{p}$-value $=0.276$} \\
\hline & Primary & 6 & 6 & 11 & 11 & \\
\hline & High school & 16 & 16 & 17 & 17 & \\
\hline & Higher secondary & 38 & 38 & 25 & 25 & \\
\hline & Degree & 25 & 25 & 27 & 27 & \\
\hline & Above degree & 14 & 14 & 20 & 20 & \\
\hline \multirow{6}{*}{$\begin{array}{l}\text { Literacy of } \\
\text { the husband }\end{array}$} & Illiterate & 2 & 2 & 2 & 2 & \multirow{6}{*}{$\mathrm{x}^{2}=6.869 ; \mathrm{df}=5, \mathrm{p}$-value $=0.231$} \\
\hline & Primary & 10 & 10 & 17 & 17 & \\
\hline & High school & 34 & 34 & 23 & 23 & \\
\hline & Higher secondary & 27 & 27 & 20 & 20 & \\
\hline & Degree & 19 & 19 & 26 & 26 & \\
\hline & Above degree & 8 & 8 & 12 & 12 & \\
\hline \multirow{2}{*}{$\begin{array}{l}\text { Mother } \\
\text { occupation }\end{array}$} & House wife & 89 & 89 & 93 & 93 & \multirow[t]{2}{*}{$\mathrm{x}^{2}=.977 ; \mathrm{df}=1, \mathrm{p}$-value $=0.323$} \\
\hline & Others & 11 & 11 & 7 & 7 & \\
\hline \multirow{5}{*}{$\begin{array}{l}\text { Husband } \\
\text { occupation }\end{array}$} & Farmer & 12 & 12 & 10 & 10 & \\
\hline & Coolie & 30 & 30 & 26 & 26 & $\mathrm{x}^{2}=4.61 ; \mathrm{df}=4, \mathrm{p}$-value $=0.330$ \\
\hline & Private & 32 & 32 & 24 & 24 & \\
\hline & Government & 6 & 6 & 10 & 10 & \\
\hline & Self employed & 20 & 20 & 30 & 30 & \\
\hline Family & Less than rs.5000 & 50 & 50 & 42 & 42 & $\mathrm{x}^{2}=1.288 ; \mathrm{df}=1, \mathrm{p}$-value $=0.256$ \\
\hline income & More than rs. 5000 & 50 & 50 & 58 & 58 & \\
\hline Domicile & Urban & 30 & 30 & 24 & 1 & $\mathrm{x}^{2}=.913 ; \mathrm{df}=1, \mathrm{p}$-value $=0.339$ \\
\hline & Rural & 70 & 70 & 76 & 76 & \\
\hline
\end{tabular}

socioeconomic status, domicile.

hypertension, eclampsia, congenital anomalies. 
* Dependent variables

Level of postpartum depression
58(58\%) respectively. Frequency and percentage wise distribution of socio-cultural factors among primi mothers

Table 2: Frequency and percentage wise distribution of sociocultural factors among primi mothers undergoing delivery in JIPMER (N=200)

\begin{tabular}{llccccc}
\hline & Socio cultural factors & \multicolumn{2}{c}{ LSCS } & \multicolumn{2}{c}{ Vaginal delivery } & Statistical \\
significance
\end{tabular}

List variable wise statistical tests to be used for data analysis: The distribution of categorical variables such as religion, educational status, type of family, marital status, economic status, domicile, family support, mode of delivery, complications of delivery, preference of the child are expressed in terms of frequency and percentage. Level of postpartum depression are also expressed in frequency and percentage, $t$-test was used for comparison between groups

\section{Results}

A total of 200 primi mothers were interviewed for this study, of which there were 100 mothers who underwent vaginal delivery and 100 mothers who had undergone LSCS. Out of the 200 primi mothers who were interviewed, table 1 shows, in LSCS and in vaginal delivery, majority of the primi mothers $52(52 \%)$ and who underwent delivery was given in table 2 . In LSCS primi mothers having pain after delivery was $72(72 \%)$ and in vaginal delivery, primi mothers not having pain after delivery was 56(56\%) and primi mothers not having breast feeding problem was $90(90 \%)$ in LSCS and $72(72 \%)$ in vaginal delivery shown in table 3.

Table 4 shows that in LSCS, majority of the patients 98 (98\%) not likely had depression and $2(2 \%)$ had depression possible. The mean and standard deviation of postpartum depression among primi mothers in LSCS is

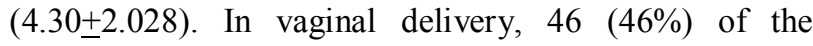
patients had depression possible, 33 (33\%) had depression not likely, $12(12 \%)$ had probable depression and few primi mothers had fairly high possibility of depression 
Table 3: Frequency and percentage wise distribution of delivery factors among primi mothers undergoing delivery in JIPMER ( $\mathbf{N}=\mathbf{2 0 0})$.

\begin{tabular}{|c|c|c|c|c|c|c|}
\hline & \multirow[t]{2}{*}{ Delivery factors } & \multicolumn{2}{|c|}{ LSCS } & \multicolumn{2}{|c|}{ Vaginal delivery } & \multirow[t]{2}{*}{ Statistical significance } \\
\hline & & $\mathbf{N}$ & $\%$ & $\mathbf{N}$ & $\%$ & \\
\hline \multirow[t]{2}{*}{ Pain after delivery } & Yes & 72 & 72 & 44 & 44 & $\mathrm{x}^{2}=16.0 ; \mathrm{df}=1$ \\
\hline & No & 28 & 28 & 56 & 56 & $\mathrm{p}$-value $=0.001 * *$ \\
\hline \multirow[t]{3}{*}{ Sex of baby } & Male & 54 & 54 & 49 & 49 & $\mathrm{x}^{2}=5.243 ; \quad \mathrm{df}$ \\
\hline & Female & 46 & 46 & 46 & 46 & $\mathrm{p}$-value $=0.073$ \\
\hline & Twins & 0 & 0 & 5 & 5 & \\
\hline \multirow{2}{*}{$\begin{array}{l}\text { Birth weight of } \\
\text { baby }\end{array}$} & Yes & 5 & 5 & 7 & 7 & $\mathrm{x}^{2}=0.335 ; \mathrm{df}=1$ \\
\hline & No & 95 & 95 & 93 & 93 & $\mathrm{p}$-value $=0.552$ \\
\hline \multirow{2}{*}{$\begin{array}{l}\text { Breast feeding } \\
\text { problem }\end{array}$} & Yes & 10 & 10 & 28 & 28 & $\mathrm{x}^{2}=10.52 ; \mathrm{df}=1$ \\
\hline & No & 90 & 90 & 72 & 72 & $\mathrm{p}$-value $=0.001 * *$ \\
\hline \multirow[t]{2}{*}{ Planned pregnancy } & Yes & 4 & 4 & 4 & 4 & $\mathrm{x}^{2}=.000 ; \mathrm{df}=1$ \\
\hline & No & 96 & 96 & 96 & 96 & $\mathrm{p}$-value $=1.000$ \\
\hline \multirow[t]{2}{*}{ Previous abortion } & Yes & 9 & 9 & 7 & 7 & $\mathrm{x}^{2}=.273 ; \mathrm{df}=1$ \\
\hline & No & 91 & 91 & 93 & 93 & $\mathrm{p}$-value $=0.602$ \\
\hline \multirow[t]{2}{*}{ Sterilized } & Yes & 0 & 0 & 1 & 1 & $\mathrm{x}^{2}=1.005 ; \mathrm{df}=1$ \\
\hline & No & 100 & 100 & 99 & 99 & $\mathrm{p}$-value $=0.316$ \\
\hline \multirow{2}{*}{$\begin{array}{l}\text { Maternal } \\
\text { comorbidities }\end{array}$} & Yes & 18 & 18 & 17 & 17 & $x^{2}=.035 ; \mathrm{df}=1$ \\
\hline & No & 82 & 82 & 83 & 83 & $\mathrm{p}$-value $=0.852$ \\
\hline \multirow{2}{*}{$\begin{array}{l}\text { Congenital } \\
\text { comorbidities }\end{array}$} & Yes & 4 & 4 & 11 & 11 & $\mathrm{x}^{2}=8.496 ; \mathrm{df}=2$ \\
\hline & No & 96 & 96 & 89 & 89 & $\mathrm{p}$-value $=0.014^{*}$ \\
\hline
\end{tabular}

Table 4: Frequency and percentage wise distribution of level of postpartum depression among primi mothers undergoing delivery in JIPMER using Edinburgh Postnatal Depression Scale $(\mathbf{N}=\mathbf{2 0 0})$

\begin{tabular}{|c|c|c|c|c|c|c|c|c|}
\hline \multirow[t]{2}{*}{ Level of postpartum depression } & \multicolumn{4}{|c|}{ LSCS } & \multicolumn{4}{|c|}{ Vaginal delivery } \\
\hline & $\mathbf{N}$ & $\%$ & Mean & SD & $\mathbf{N}$ & $\%$ & Mean & SD \\
\hline Depression not likely & 98 & 98 & & & 33 & 33 & & \\
\hline Depression possible & 2 & 2 & 4.30 & 2.028 & 46 & 46 & 10.10 & 2.932 \\
\hline Fairly high possibility of depression & 0 & 0 & & & 9 & 9 & & \\
\hline Probable depression & 0 & 0 & & & 12 & 12 & & \\
\hline
\end{tabular}

Table 5: Comparison between the level of postpartum depression among primi mothers undergoing delivery in JIPMER using Edinburgh Postnatal Depression Scale $(\mathbf{N}=\mathbf{2 0 0})$

\begin{tabular}{llll}
\hline $\begin{array}{c}\text { Level of } \\
\text { postpartum } \\
\text { depression }\end{array}$ & $\begin{array}{l}\text { Mean with } \\
\text { standard } \\
\text { deviation }\end{array}$ & $\begin{array}{c}\text { ' } \mathbf{t} \text { ' test } \\
\text { value }\end{array}$ & 'p' value \\
\hline LSCS & $4.30 \pm 2.028$ & -16.27 & $0.001 * *$ \\
\hline Vaginal delivery & $10.10 \pm 2.932$ & & \\
\hline$* * \mathrm{p}<0.001$ significant & & \\
\hline
\end{tabular}

$9(9 \%)$. For postpartum depression among primi mothers mean and standard deviation in vaginal delivery is

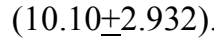

Comparison between the levels of postpartum depression among primi mothers who underwent delivery using Edinburgh Postnatal Depression Scale is shown in table 5 .
The mean and standard deviation of postpartum depression among primi mothers undergoing delivery in LSCS and vaginal delivery is (4.30 \pm 2.028$)$ and (10.10+2.932).

\section{Discussion}

The study was aimed to assess the prevalence and the level of postpartum depression among primi mothers undergoing delivery in JIPMER. A total of 200 primi mothers underwent vaginal delivery and LSCS within 3-5 days following delivery were assessed. The primary objective of the study was to assess the prevalence of postpartum depression among primi mothers in JIPMER. The study revealed that the prevalence of postpartum depression among primi mothers is $12 \%$. 
A systematic review and meta-analysis was conducted on postpartum depression in India revealed that the prevalence of postnatal depression was $22 \%{ }^{5}$. The South Indian study conducted on postnatal depression in Karnataka revealed that the prevalence of postpartum depression was about $13.7 \%{ }^{14}$. The study was conducted by Poomalar GK in Puducherry found that the prevalence of postnatal depression was $10.6 \%{ }^{15}$. In contrast to this study, the prevalence was found to be higher (12\%) in the present study.

The secondary objective of the study was to compare the level of postpartum depression among LSCS and vaginal delivery mothers. This study found that the higher level of postpartum depression is present among vaginal delivery mothers than the LSCS mothers.

In contradicting to the present study, the study conducted in Karnataka on 2017 revealed that the level of postpartum depression was high among the LSCS mothers than the vaginal delivery mothers ${ }^{16}$ but this study include both primigravida and multigravida mothers. However, there is a lack of evidence in comparison of postnatal depression among primi mothers who underwent vaginal delivery and lower segment caesarean section in India.

\section{Conclusion}

The findings of the study revealed that the $12 \%$ of the primi mothers had probable depression and also, they need to be counselled. In LSCS, majority of the patients 98(98\%) had depression not likely and 2 (2\%) had depression possible. In vaginal delivery, majority of the patients 46 (46\%) had depression possible, 33 (33\%) had depression not likely, 12 (12\%) had probable depression and few primi mothers had fairly high possibility of depression 9(9\%). It also enabled us to know the need for awareness program on postnatal period and its complications and management at the time of antenatal period itself may help to alleviate the mothers from getting into depression which will directly and indirectly affects the mother, baby and the whole family itself.

\section{Conflict of interest: None. Disclaimer: Nil. \\ References}

1. Sword W, Landy KC, Thabane L, Watt S, Krueger $\mathrm{P}$, Farine D, et al. Is mode of delivery associated with postpartum depression at 6 weeks: a prospective cohort study? BJOG: Int J Obstet Gynaecol. 2011; 118(8): 966-77.

2. McCoy SJB, Beal JM, Saunders B, Hill EN, Payton ME, Watson GH. Risk factors for postpartum depression: a retrospective investigation. J Reprod Med. 2008; 53(3): 166-70

3. Chaaya M, Campbell OMR, Kak FE, Shaar D, Harb $\mathrm{H}$, Kaddour A. Postpartum depression: prevalence and determinants in Lebanon. Arch Women's Mental Health. 2002; 5(2): 65-72

4. Savarimuthu RJ, Ezhilarasu P, Charles H, Antonisamy B, Kurian S, Jacob KS. Post-partum depression in the community: a qualitative study from rural South India. Int J Soc Psychiatry. 2010 January; 56(1): 94-102.

5. Upadhyay RP, Chowdhury R, Salehi A, Sarkar K, Singh SK, Sinha B, et al. Postpartum depression in India: a systematic review and meta-analysis. Bull World Health Organ. 2017; 95(10): 706-17C.

6. Warner R, Appleby L, Whitton A, Faragher B. Demographic and Obstetric Risk Factors for Postnatal Psychiatric Morbidity. Br J Psychiatry. 1996; 168(05): 607-11.

7. Stotland N, Stewart D. Psychological aspects of women's health care. 2nd ed. Washington: American Psychiatric Press; 2001.

8. Surkan PJ, Kennedy CE, Hurley KM, Black MM. Maternal depression and early childhood growth in developing countries: systematic review and metaanalysis. Bull World Health Organ. 2011; 89(8): 608-15D.

9. Cox JL, Holden JM, Sagovsky R. Detection of postnatal depression: development of the 10-item Edinburgh postnatal depression scale. $\mathrm{Br} \mathrm{J}$ Psychiatry. 1987; 150:782-6.

10. Jacobsen T. Effects of postpartum disorders on parenting and on offspring. In Miller LD, ed. Postpartum mood disorders. Washington: American Psychiatric press, 1999:119-39.

11. Stewart DE, Robertson E, Dennis CL, Grace SL, Wallington T. Postpartum depression: literature review of risk factors and interventions. Toronto: University Health Network Women's Health Program; 2003. Available from: http:// www. who.int/mental_health/prevention/ suicide/lit_review postpartum_depression.pdf 
The New Indian Journal of OBGYN. 2020 (January-June); 6(2)

12. Dennis CL, Stewart DE. Treatment of postpartum depression, part 1: a critical review of biological interventions. J Clin Psychiatry. 2004; 65(9):124251.

13. Benjamin D, Chandramohan A, Annie IK, Prasad J, Jacob KS: Validation of the Tamil version of Edinburgh post-partum depression scale. J ObstetGynecol India. 2005; 55: 241-43.

14. K Kruthika, Udayar SE, Mallapur M.D. An epidemiological study of postnatal depression among women availing maternal health services in rural areas of Belagavi, Karnataka, India. Int J Community Med Public Health. 2017; 4(3): 759-63.

15. Poomalar GK, Arounassalame B. Impact of sociocultural factors on postpartum depression in South
Indian women. Int $\mathbf{J}$ of Reprod Contracept Obstet Gynecol. 2014; 3(2): 338-43.

16. Mahishale AV, Bhatt JA. Comparison of level of depression among mothers with lower segment cesarean section and vaginal delivery: A crosssectional study. J Sci Soc. 2017; 44: 15-9.

\section{Gowsalya Selvam ${ }^{1}$, Janarthanan Balasubramanian²,} Sairem Mangolnganbi Chanu ${ }^{3}$

${ }^{1}$ B.Sc. Nursing IV year, Nursing student, College of Nursing, JIPMER, Puducherry; ${ }^{2}$ Tutor, College of Nursing, JIPMER, Puducherry; ${ }^{3}$ Assistant Professor, Department of Obstetrics and Gynaecology, JIPMER, Puducherry. 